\title{
Pre-Engineering Education Collaborative at Four: Approaching the Final Phases
}

\section{Dr. Robert V. Pieri, North Dakota State University}

Dr. Robert Pieri is Professor of Mechanical Engineering at North Dakota State University (NDSU) in Fargo, ND. He has many conference publications on engineering education and design. His primary interest areas include: Engineering Education, CADD, Design, Fracture Mechanics, Materials Science and Alternative Energy Options. Prior to joining NDSU, he worked for Allied-Signal Corporation and in the aircraft supply industry. Prior to his industrial experience he taught for 10 years at the US Air Force Academy. Prior to his time at USAFA, Bob was a Research \& Development Engineer with the US Air Force, studying problems of pollution in the earth's atmosphere. One of his dissertations involves the environment and policy decisions that could affect it. Dr. Pieri has degrees from the University of Massachusetts at Amherst, Thayer School at Dartmouth College and Carnegie - Mellon University in Pittsburg, Pennsylvania. For the academic year 2003- 2004, Bob was on the faculty at Turtle Mountain Community College in Belcourt,N.D. where he taught Math and Engineering classes. This is the basis for his current interest in Native Americans into Engineering. Bob, originally from the northeast area of the USA, has been a resident of Fargo, ND since 1996.

\section{Mr. Timothy D Legg, North Dakota State University}

Timothy Legg, is an 2004 alumni of Iowa State University's Computer Engineering program. He worked and consulted in the Chicago area in topics as diverse as industrial coatings, semiconductor fabrication and lean manufacturing. As of 2011, he was additionally enlisted at Cankdeska Cikana Community College for the NSF's PEEC program to teach Pre-Engineering and Mathematics courses. In 2015, he has enrolled as a graduate student at North Dakota State University

\section{Ms. Ann Marie Vallie, Turtle Mountain Community College}

Ann Vallie graduated from North Dakota State University in 2010 with a B.A. in Electrical Engineering. Joined Turtle Mountain Community College in 2011 as the Pre-Engineering Instructor for the PreEngineering Education Collaboration which is funded through NSF.

\section{Lori Alfson, Fort Berthold Community College \\ Dr. Joshua Jason Mattes, Sitting Bull College \\ Mr. Michael Maloy Parker, Cankdeska Cikana Community College}

Mike Parker received a BS in Mechanical Engineering from North Dakota State University. He served in the US Army as a reliability engineer and vehicle test officer. He has been an agricultural producer in his home state of ND as well as being involved in local manufacturing and oil well hydraulic fracturing. He is currently an instructor at Cankdeska Cikana Community College in the Pre-engineering program.

\section{Dr. G. Padmanabhan, North Dakota State University}

G. Padmanabhan, Ph. D., P. E., M. ASEE, F. ASEE is a professor of civil engineering at North Dakota State University (NDSU), Fargo, North Dakota. He has been on the NDSU faculty for more than 30 years teaching and engaging in research. His expertise is in water resources systems and modeling. $\mathrm{He}$ served as the Director of North Dakota Water Resources Research Institute for the last 12 years. He is a long standing member of ASEE. He has been active in STEM education outreach activities to North Dakota Native American students at the college, high and middle school levels for the last 15 years. He has received funding from the Office of Naval research, National Science Foundation, and NASA for his STEM outreach activities directed toward North Dakota Native American students. He has presented in ASEE conferences and published in their Proceedings. He has also been involved in organizing ASEE North Midwest Region conferences. 


\title{
Pre-Engineering Education Collaborative at Four: Approaching the Final Phases
}

\begin{abstract}
:
This paper will contain a short introduction and description of the Pre-Engineering Education Collaborative program sponsored by NSF and enacted at North Dakota State University, NDSU. PEEC is a program to expand the inclusion of Native American students into the engineering career field while at the same time opening awareness of the opportunities available in tribal communities for engineering talent. It is proposed that such an inclusion will expand the opportunities for engineering career fields on the reservation. A description will be provided as to how the initial concepts have evolved during the years of operation. Also contained within the paper will be a description of the serendipitous events relating to resources, administration staff and students success stories and the implications they have for future successes. Following that will be a discussion of the lessons to be learned from the less than optimal activities and the resulting opportunities in the context of the evolving nature of educational responses. Finally, some approaches will be suggested to obtain positive results from these situations. Future needs and prospects will be discussed to include follow-on funding and extensions to other tribal colleges and mainstream institutions.
\end{abstract}

\section{The Program \& Justification for Focus:}

The Pre-Engineering Education Collaborative, PEEC, is a rather unique program funded by the National Science Foundation, NSF, in the summer of 2010. It is a way to get tribal colleges and universities, TCUs, to work with mainstream institutions to develop an engineering pipeline through TCUs to graduate Native American students from four-year mainstream institutions into the engineering profession. If one believes that engineering resources should be applied in proportion to the local need then tribal communities, on some particular reservations, are great places for engineering application. As enacted, the program had funding from two NSF directorates, Engineering and Human Development and as a result had two primary goals. One of the goals was the development of engineering capable curriculum and students at TCUs. The second goal was to look at educational approaches to bring minority students into the engineering profession.

The focus of this paper will be on what could be expressed as the following proposal: "What does it take to get more Native American students through an engineering program?”

These NSF backed goals have some common characteristics while at the same time being operationally distinct because of public law. The obvious commonality is that both goals aim at producing more engineering graduates from an underrepresented population. The operational distinction comes from the requirement that no funding from the particular agency sponsoring this program within the Human Development Directorate at NSF is permitted, by law, to go to 
any mainstream institutions. This was to some extent prompted by the title "collaborative" put on the program which implied direct funding to participating institutions providing for more equity in decision-making, particularly for TCUs. During the development of the program this was not seen as a huge constraint but it was only recognized as such later on. It will be addressed later in this paper. For more information on the funding, see NSF solicitation 10-501.

This collaborative approach actually has several possible positive benefits to it, some of which include the following: It provides for early and continued association between faculty and staff from the two types of institutions. This association is able to address questions of curriculum development and administrative procedures tailored to the students who eventually make the transfer. It also provides both groups of academics with some background regarding the operation of the other type of institution to a level not known before because of the course transfer issues. Over time this allows for a particularly strong sense of trust to be developed among collaboratives, as expanded upon below. Curriculum formulation in support of engineering education, to an ABET approved level, necessitates faculty professional development for science, mathematics and technology instructors as well as the "rare" engineering instructor on staff at the TCU. These levels of interaction eventually strengthens individual collaborations between academics in the program, which heightens concern for the students on either side of the transition process. Additional benefits also accrue to the TCUs by avoiding the most costly segment of engineering education: laboratories woven throughout final two years of most programs. The students would also benefit from taking basic engineering courses, i.e. math and science courses at the local institution closer to their "homes" with a relative small class size. A benefit to the mainstream institution would be that they gain diversity in their graduating classes without proportional expansion of general student recruiting activities. It is also seen that there might be some nontrivial benefit to participating faculty at mainstream institutions with respect to experiencing effective teaching approaches for diverse students. Both groups of academics recognize the opportunity for development of infrastructure in the local tribal communities in response to some serious needs of their populations.

\section{Initial Concepts \& Operation:}

Initial proposals seeking funding were diverse and dynamic enough to cause NSF to double the actual awards from 2 to 4 . This expanded number also caused the focus to not only include Native American students but Pacific island students as well. In all proposals, groups of indigenous students would receive fundamental engineering courses to include basic sciences and mathematics to Associates of Science degree levels. All proposals included some student recruitment activities, recognizing the need to establish the intake of the student pipeline to be somewhere in the high school years. All proposals also recognized the need for community outreach to exemplify the opportunity available for local engineering talent to work on infrastructure development needs within their respective communities. Beyond these areas of 
commonality, each of the four awarded collaboratives were individualistic and had particular approaches to meet the fundamental needs of the grant.

The PEEC: NDSU proposal was rather unique within this small group of collaboratives in that it was the only proposal that brought together four autonomous TCUs: Cankdeska Cikana, Turtle Mountain Community College, Fort Berthold Community College and Sitting Bull College, with a singular mainstream institution, NDSU. Two of the four funded collaboratives brought together two mainstream institutions and a single TCU while the fourth collaborative brought satellite campuses within the same state University system together with the main campus in that system.

As envisioned in the original proposal, PEEC: NDSU was to have the collaborative of TCUs working with the mainstream institution under the guidance of three advisory boards: Administrative, Instructional and Professional. It was envisioned that these three advisory boards would act as guides for the proposal. As envisioned, the role of the Administrative Advisory Board, composed of the PI's from all of the collaborating institutions, would be to cooperate and coordinate on items to ensure a smooth flow of the educational process for the students to include the acceptance of classes for exchange credit with minimum hassle and maximum efficacy. The Instructional Advisory Board was responsible for developing curriculum and utilizing shared resources for the betterment of the entire cadre of students independent of institutional boundaries. The Instructional Advisory Board would be responsible for ensuring that all classes met the criteria of the ABET accreditation commission. This board was led by the full professor from NDSU, an individual familiar with multiple ABET evaluation visits. This board would also act as the direct interface with the students in the program. The Professional Advisory Board actually had two rules to play within the proposal. This board was comprised of both the engineering instructors within the program and Native American engineering professionals in the area and region. The first responsibility of this board of engineers was to ensure the relevance of the instruction with respect to current engineering practice. With the help of the instructor members, this board could translate that professional need into curriculum course requirements for the students. In addition the Professional Advisory Board served as a unique role model for the engineers in-training since the board members had personally experienced nearly all of the same out-of-the-classroom challenging situations as these would be practitioners could foresee. In addition the Professional Advisory Board provided a perspective on employment opportunities; several members had their own businesses. This was clearly a designed step toward the post-graduation entry into the profession, an aspect of the original proposal. Of the three advisory boards, the Instructional Advisory Board was the most active but more will be said below.

The mechanics of the proposal stated that the students would start at the TCUs by taking an introductory engineering course to be offered through an interactive video network, IVN, to each of the sites from NDSU. Each TCU was responsible for putting together a program of 
humanities and social sciences and mathematics through calculus II with a minimum chemistry and physics for the core sciences. The proposal stated that fundamental engineering courses such as statics, dynamics, surveying \& thermodynamics, would be offered in a shared/distance education mode for several reasons. The first would be that the total student numbers would not be very large, about one to three per institution. Another reason was that the engineering expertise at anyone institution did not cover all disciplines. But perhaps the most driving rationale was that by teaching in this multi-classroom fashion it would help to develop a student cadre approach to the pursuit of a degree. This is a valued support tool for student learning (a web search for "student cadre in education" produced in excess of 55 million hits). As initially envisioned, the proposal had several cadre groups based upon program entry and transferal to the mainstream institution, resulting in as many as eight cadres. It was thought that these cadres would aid their student members in coping with classroom and out-of-classroom situations. By having these cadres come together and learn to support each other it was believed that the key essence of peer to peer support would be provided and that it would be helpful beyond simply academic advising. The "zeroth" cadre within the program would be existing Native American students at NDSU who could act as liaisons with the TCU students as they progress through their TCUs program and approached the transfer to NDSU.

A key feature of the proposal was a 12 day summer camp held at NDSU with all the participants of the PEEC program coming together for an orientation to the campus and demonstrations of items that may be helpful towards long-term academic survival and individual development. The programs on campus were intended to be a mix of basic science demonstrations, math refresher sessions and campus orientation. In addition to the typical presentations from admissions, financial aid, housing and local cultural connections, this summer camp included an equine session on management and leadership principles. At the core of the summer camp was an intense three credit course on surveying, thermodynamics or digital circuit design, depending on student level and interest. Instructors used in these courses were either the same as used during normal semesters or experienced prior summer camp instructors. The purpose for this course was not simply to transfer the knowledge about the topic, but to do the transfer in an extremely intensive fashion to simulate the most hectic part of the semester to be experienced upon transfer. Although this course was very intense it had safety features in place to prevent the total loss of student motivation. These included such things as a low student-to-mentor ratio, hands-on learning by doing and readily available help sessions. Of particular interest was the students attitude in completing all of the assigned work.

This was the designed program at the beginning of the first year. A summary of this collaboration and the other funded collaborations by Paul Boyer at: http://online.swc.tc/peec/?p=149 . 


\section{Evolved Practices \& Impact on Innovation:}

Reality can turn around the best of intentions. The program described above was soon modified when finding engineering instructors for the different TCUs proved to be problematic. One TCU had an instructor identified before funding was awarded and is still part of the program. Another found instructor within three weeks of funding and he participated 3 years in a number of courses but was caught up in some administrative changes and moved on. However, that same TCU found a backup instructor and then a second backup instructor to help. The third TCU took several months to find an instructor and he remained at the institution for one year and was lured away by a national engineering firm in the area. He was however replaced within approximately a six months period and that replacement has stayed two years. However, the fourth institution took over two years to find an engineering instructor but when they did he turned out to be the most experienced instructor. Since the initial hiring it seems that there has been some turnover/changes on about an 18 month cycle in the program has had to cope with this. This is highlighted the need for an ongoing professional development aspect to the proposal which is actually a positive component in that it formalizes in a fashion this need for continual improvement.

The students had a slightly lower turnover rate, but there was also a large number of new faces without significant increase in numbers. The introductory engineering course would typically have initial enrollments of 7 to 13 students each semester but within 3 to 4 weeks that enrollment would typically fall to half of the initial number. Both the student and instructor situations were acerbated by a nationally recognized economic boom.

Even weather became an issue with initial plans to teach the introductory engineering course in a highbred distance education on-site mix. Several times significant winter storms caused the visited TCU to be shut down while satellite TCUs were up and running. This was made worse by technological problems with the IVN system and connectivity problems. It seems that the 4 to 5 courses scheduled each semester for this particular program would strain that communication system to its limit at many institutions. This forced consideration of including technology in a more portable source such as Skype or Polycom for portable units. This had some level of success but because of the autonomous nature of each TCU and NDSU, technological standards were difficult to maintain. The good news from this evolution was that the system of distance education with periodic face-to-face contact for nearly all participants came into being. The mechanics of this were such that on one Friday in each month of the semester a central site was chosen for the introductory engineering class to gather in many of the other core engineering classes to also come together. This allowed several instructors face time with students that might usually be more than 350 miles away. This cemented the feeling of a supportive cadre awaiting to transfer. For all other days during the semester the normal distance education meeting times were used for "normal” class activities. 
The fundamental definition of the cadres were broken down into basically to all of the students at the four TCUs comprised one cadre and the other cadre was composed of the students who had transferred from the TCUs to NDSU. This came about as a result of the summer camp and the evolution of the transferring students to NDSU and establishment of a sort of status for the students that have transferred already or directly enrolled at NDSU. The summer camp has evolved and added a significant activity in a scenario-based role playing learning opportunity in which the camp members are broken into two teams of engineering interns working in different companies addressing a comparable problem from the Native American community. Within a short time these two teams have to do some background research, make an initial proposal, then conduct a technical meeting (that is recorded for feedback and assessment over several years) to ensure the quality of technical communication and finally provide a written preliminary summary of suggested steps to mitigation of the situation. This activity resulted from a suggestion by a member of the Administrative Advisory Board as to how to ensure the quality and engagement of the students in the program.

\section{Lessons Learned \& Opportunities for Improvements:}

All of the above has provided all the advisory boards with opportunities to modify and revisit initial assumptions for the program. As program termination nears, all stakeholders seem to appreciate the value added to their curriculums by the inclusion of the engineering options. The aforementioned economic boom as in recent months been impacted by global market forces and have highlighted the continually changing nature of education and in particular engineering education.

The primary lesson learned from the program is the value of the individual. Whether it is student or instructor or principal investigator or technology scheduler, they all play a role and some play that role better than others. Motivation and coaching tends to be a key component toward improving the performance. In the theater arts world this may be considered "inspired direction", that is to say getting the most out of the individual as is possible in the situation. Key to that is the recognition of the individual and how that individual can be motivated or brought in to the larger system where they can help define their own role in support of the entirety.

The utilization of underrepresented participants in engineering has not diminished. If anything the attractiveness of individuals coming from a culture that highly values sustainability and environmental consideration seems to be an even greater demand.

\section{Conclusions and Visions for Sustained Program:}

The basic conclusion of this paper is that the numbers of engineering students going into the profession can be increased but not without significant application of time and resources. Although quantitative measures of these time and resource applications are institution specific (violating the double-blind requirement of this paper) the range is clearly 2 to 3 times beyond the normal expectations for students. The critical part of most NSF programs is sustainability, and 
toward that, the critical question is: "What will make this program self-sustainable at the end of the funding?” The typical measures of success, such as the numbers of PhD's produced or companies started or patents filed, doesn't seem to fit in this situation. A philosophical question hinges on the value of the individual and that in turn seems to hinge on the value of what the individual can do for society or their own community. As stated above, reservation-based tribal communities can be some of the most impoverished and challenged communities in this nation. The opportunities for individuals with engineering training to be able to facilitate positive steps to improve the situation would seem to be huge. This program has the fundamental components that can allow that to take place, with the right people.

The author wishes to thank NSF for its support through Pre-Engineering Education Collaborative Program from the Directorates of Engineering and Human Development.

\section{References:}

Introduction: BLS Statistics by Occupation, Audrey Watson, Bureau of Labor Statistics, http://www.bls.gov/spotlight/2014/occupations/home.htm, August , 2014

Percentage of persons age 25 and over with high school completion or higher and a bachelor's or higher degree, by race/ethnicity and state: 2008-10, National Center for Education Statistics, , http://nces.ed.gov/programs/digest/d12/tables/dt12_015.asp , accessed 2015

Undergraduate enrollment at all institutions, by race, ethnicity, citizenship, sex, and enrollment status: 2002-12, (Women, Minorities, and Persons with Disabilities in Science and Engineering, NSF Data Table), http://www.nsf.gov/statistics/2015/nsf15311/tables/pdf/tab2-1.pdf , 2015 